(1964).

9) 本多敏雄 : 炭素, 4, 19 (1966).

$$
\mathrm{c}^{2}
$$

Rapid determination of micro-amounts of oxalate ion using two-step flow-coulometry. Sorin Kinara, Tadashi Yamamoto, Kenji Motojima* and Taitiro FujinaGA** (*Japan Atomic Energy Research Institute, Tokai-mura, Naka-gun, Ibarakiken; **Department of Chemistry, Faculty of Science, Kyoto University, Sakyo-ku, Kyoto-shi)

A rapid method for determination of micro amounts of oxalate ion has been developed by using two-step flow-coulometry. Carbon fiber is used for working electrodes. Supporting electrolyte solution (0.5 M sulfuric acid) is flowed through the flow-coulometric cloumn electrode and 5 to $10 \mu \mathrm{l}$ of sample solution containing $10^{-5}$ to $10^{-1} M$ oxalate ion is injected. Since reduction or oxidation of diverse ions occurs at the first-step column electrode, of which working electrode potential is adjusted to $+1.20 \mathrm{~V}$ vs. Ag$\mathrm{AgCl}$, the interference in the determination of oxalate ion is eliminated. Then the sample solution is flowed into the second-step column electrode, where oxalate ion is oxidized. At $+1.60 \mathrm{~V}$ vs. $\mathrm{Ag}-\mathrm{AgCl}$, oxalate ion decomposes to carbon dioxide and hydrogen ion with two-electron oxidation reaction. In the range of $0.2 \sim 5.0 \mathrm{M}$ sulfuric acid electrolyte, the reaction occurs quantitatively. The flow rate of electrolyte is sufficient between 1 and $15 \mathrm{ml} / \mathrm{min}$. The quantity of electricity at the second-step column electrode gives the amount of oxalate ion. Time required for the determination is within $20 \mathrm{sec}$. One tenth to $10 \mathrm{n}$ moles of oxalate ion has been determined within an error of $4 \%$, and $1 \mu$ mole within $2 \%$. Cerium, chromium, iron and uranium do not interfere with the determination of oxalate ion. Although aluminum and thorium form stable complex ion and precipitate, respectively, their interference can be eliminated by increasing the sulfuric acid concentration from 0.5 to $2.5 \mathrm{M}$. Other carboxylic acids such as citric, formic, glycolic and tartaric acid are not oxidized at +1.60 $\mathrm{V}$ vs. Ag-AgCl. The interference from hydrogen peroxide can be eliminated by the addition of vanadyl ion.

Decomposition of oxalate ion by light has been studied by using the proposed method. When the concentration of oxalate ion is lowered, the effect of light becomes more pronounced. In the presence of metal ions which have more than two stable oxidation states in aqueous solution. e.g., iron and uranium, oxalate ion decomposes more quickly. Electrode reactions of other organic acids (glyoxalic acid, formic acid, tartaric acid, etc.) have been also studied.

The two-step flow-coulometric method for the determination of oxalate ion has the following advantages over the spectrophotometric and titrimetric methods: small sample size, speediness, high precision, and possibility of remote controlled analysis.

(Received Oct. 11, 1971)

\title{
プラスチック容器中の無機介在粒子
}

\author{
黒 羽 敏 明*
}

(1971 年 10 月 22 日受理)

\begin{abstract}
高純度物質, 分析用試薬などの容器として用いられるプラスチック容器について, 含まれる介在粒子 の大きさ, 数量, 分布, 組成を研究した. 主としてテフロン試薬びえについて検討したが, 介在粒子の 大きさは数 $\mu$ から $200 \mu$ 程度で多くは $50 \mu$ 以下であった. これらの粒子は全体に分布し特に顕著な偏 在は見られなかった，粒子の主成分として鉄，チタン，マグネシウム，カルシウム，ケイ素が認められ た. 粒子の数は，テフロン試薬びえでは $7 \sim 20 \times 10^{3}$ 個 $/ \mathrm{cm}^{3}$ ，ポリェチレン試薬びえでは， $9 \times 10^{2}$ 個/ $\mathrm{cm}^{3}$ ，ポリプロピレン試薬びえでは $7 \times 10^{2}$ 個 $/ \mathrm{cm}^{3}$ であった．介在粒子を代表する成分として鉄を定量

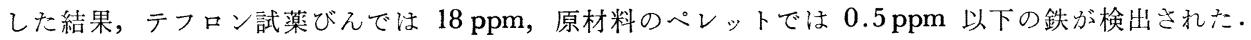

$$
1 \text { 緒 } \overrightarrow{\overline{\overline{1}}}
$$

近年，純物質が多くの研究者によって研究され，しだ

$*$ 古河電気工業株式会社中央研究所 : 東京都品川区二 葉 2 丁目
いにその重要性が涩識されてきた・高純度物質の製造, 分析と並えで容器の問題は純物質を諭ずる場合無視する ことはできない：これらは相互に関連しあうもので，い ずれが欠けても純物質を得ることは不可能である.

各種試薬用容器としてポリエチレンがすでにコマーシ 
ヤルベースにのって広く利用されているが，耐薬品性の 観点から完全なものとはいえず，その使用には限界があ る.これに対してテフロンの持つすぐれた性質は，ポリ エチレン，ポリプロピレン，ポリスチレンあるいは他の プラスチックにまさるものであり，耐薬品性，耐熱性を 兼ね僃えたものとして現在のところ数あるプラスチック 中最高のものである.

純物質の貯蔵用あるいは運搬用容器としてこのすぐれ た性質を有するテフロンを利用すべく意図されるのは当 然であるが，利用に際して容器の純度が問題となる. も ちろえテフロンそのものは高純度試薬あるいは純物質に 対する污染の要因とはならないが，テフロン中に介在す る微小な金属粉あるいは無機酸化物が問題になる．無機 物污染が皆無のテフロン容器が供給されるのが理想であ るが，現在入手できる製品にはこれを期待することがむ ずかしいといわれている1). すなわちテフロン容器中に は, 大は約 $200 \mu$ 程度, 小は数 $\mu$ の大きさの金属粉ある いはかなりの量の無機酸化物が見いだされる2).

本報はテフロン容器中に含まれるこれらの金属粉ある いは無機酸化物（以後これらを介在粒子と呼ぶ）につい て数量, 成分, 分布などをマイクロスコープ, レーザー マイクロプローブを利用して明らかにしたものである.

\section{2 装置}

マイクロスコープ: Leitz 社製, 偏光 $\cdot$ 反射 · 透過測 定用， $\times 50 ＼times 150$ で測定した.

レーザーマイクロプローブ：Spex 社製, 分光器は Spex 1800, f/6.3, 回折格子 1200 本 $/ \mathrm{mm}$.

\section{3 実験}

\section{1 数}

$\mathrm{A}$ 社製のテフロン，ポリエチレンおよびポリプロピレ ン試薬びえと，これに用いた原料ペレットについてほぼ $5 \mu$ 以上の介在粒子の数量をマイクロスコープによって 測定した・結果を Table I に示した.

Table I Number of particles in pellets and bottles

\begin{tabular}{|c|c|c|c|c|}
\hline Sample & & $\begin{array}{l}\text { Thickness } \\
(\mathrm{mm})\end{array}$ & Number $/ \mathrm{cm}^{2}$ & Number $/ \mathrm{cm}^{3}$ \\
\hline Teflon & $\left\{\begin{array}{l}\text { pellet } \\
\text { bottle }\end{array}\right.$ & $\begin{array}{l}0.41 \\
1.21\end{array}$ & $\begin{array}{l}128,146 \\
868, \cdot 841\end{array}$ & $\begin{array}{l}3.3 \times 10^{3} \\
7.1 \times 10^{3}\end{array}$ \\
\hline $\begin{array}{l}\text { Polyethylene } \\
\text { (Conventional) }\end{array}$ & $\left\{\begin{array}{l}\text { pellet } \\
\text { bottle }\end{array}\right.$ & $\begin{array}{l}0.88 \\
1.08\end{array}$ & $\begin{array}{lr}23, & 28 \\
98, & 103\end{array}$ & $\begin{array}{l}2.9 \times 10^{2} \\
9.3 \times 10^{2}\end{array}$ \\
\hline $\begin{array}{l}\text { Polvethylene } \\
\text { (Linear) }\end{array}$ & $\left\{\begin{array}{l}\text { pellet } \\
\text { bottle }\end{array}\right.$ & $\begin{array}{l}0.61 \\
0.76\end{array}$ & $\begin{array}{lr}12, & 9 \\
45, & 48\end{array}$ & $\begin{array}{l}1.7 \times 10^{2} \\
6.1 \times 10^{2}\end{array}$ \\
\hline Polypropylene & $\left\{\begin{array}{l}\text { pellet } \\
\text { bottle }\end{array}\right.$ & $\begin{array}{l}0.85 \\
0.50\end{array}$ & $\begin{array}{rr}9, & 6 \\
37, & 33\end{array}$ & $\begin{array}{c}9 \times 10 \\
7.0 \times 10^{2}\end{array}$ \\
\hline
\end{tabular}

The number of particles in pellets was counted after hot-pressing.
また同様に， B 社製の厚さの異なる 4 種類のテフロン シートと試薬びえについて測定した結果を Table II に 示した.

Table II Number of particles in Teflon sheets and bottle

\begin{tabular}{ccrrr}
\hline \hline Sample & Thickness $(\mathrm{mm})$ & \multicolumn{2}{c}{ Number $/ \mathrm{cm}^{2}$} & Number $/ \mathrm{cm}^{2}$ \\
\hline Sheet A & 0.05 & $52, \quad 50$ & $10.2 \times 10^{3}$ \\
" B & 0.13 & $167, \quad 162$ & $13.1 \times 10^{3}$ \\
" C & 0.25 & $252, \quad 219$ & $9.4 \times 10^{3}$ \\
" D & 0.50 & $853, \quad 904$ & $17.5 \times 10^{3}$ \\
Bottle & 0.63 & 1244,1404 & $20.8 \times 10^{3}$ \\
\hline
\end{tabular}

Table I から明らかなように，原料ペレット，試薬び えともテフロン製品は，他のポリエチレン，ポリプロピ レン製品に比べて多数の介在粒子が認められた・また同 種材料間では，原料ペレットに対して試薬びえ中に多数 の介在粒子が存在し, 量的には約 5 倍程度になっている ことが認められた。これは試薬びん加工工程で污染が著 しいこと, すなわち加工時の温度と粘度, それに伴う加 工機の材質などが影響していることを示唆するもので， 加工温度の高いテフロン中により多くの介在粒子が存在 していることは，この間の事情をよく表わしている。 た介在粒子の大小関係を見ると，ペレットではいずれも $5 \sim 10 \mu$ 程度であるのに対して, 試薬びんでは数十 $\mu$ の ものが見られ，ときには $200 \mu$ 程度のものが存在してい る. この大小関係からも加工中に污染が起きていること がわかる。

Table II の結果は, いずれも $10^{4}$ 個 $/ \mathrm{cm}^{3}$ 程度の介在 粒子が存在していることを示している. 介在粒子の大き さは厚さに比例して大きくなり，特に試薬びんでは他の シートに比べて大きな介在粒子が認められた.

以上の結果は，従来あまり意識されていなかったプラ スチック中の無機介在物が意外に多いことを示してお り，分析に従事するものとして無視できない問題のよう に思われる。

\section{2 分 布}

主として黒色あるいは茶かっ色の介在粒子が容器全体 に分布しているが，ここでは分布の状態を容器の内側か ら外側にかけて測定した. 結果を Fig. 1 に示した. Fig. 1 の[A]は 10〜 $50 \mu$ の介在粒子について， [B] は $50 \mu$ 以上の介在粒子についての分布を示したもので ある. 原料ペレット中には $10 \mu$ 以上の介在粒子がほと えど存在していないので，ここに示した $10 \mu$ 以上の介 在粒子は容器加工工程で混入したものとみなしてさしつ 


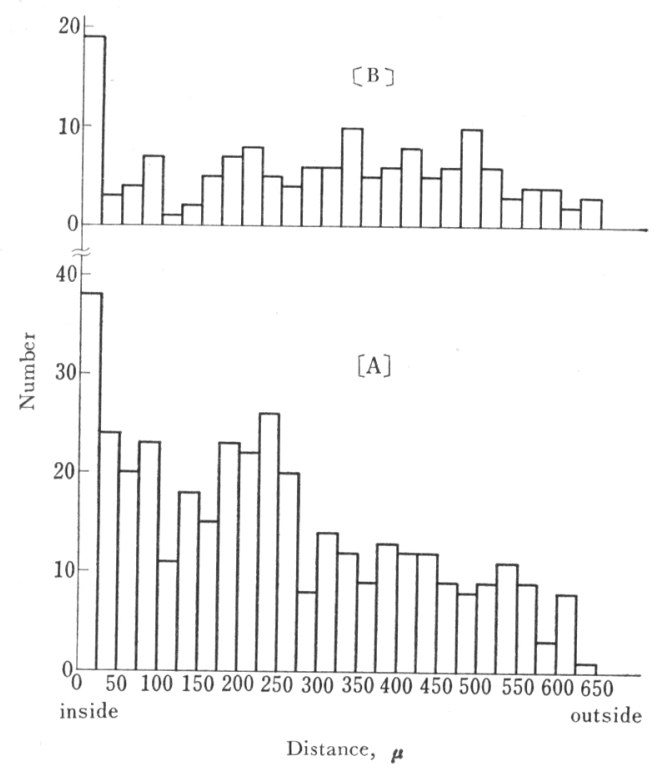

Fig. 1 Distribution of particles in Teflon bottle from inside surface to outside surface [A] Particle size : $10 \sim 50 \mu, n: 378 ; \quad$ [B] Particle size : $50 \mu$ up, $n: 149$

かえないものと判断される。

Fig. 1 に見られるように, 介在粒子は厚さ方向の全体 に分布しているが，そのなかでも比較的内側に多く見ら れるようである。ことに内側から数十 $\mu$ の所, 容器とし ては介在粒子の存在を最忌避しなければならない部分 に多くの介在粒子莸認めた。 介在粒子はいずれもテフロ ン膜でおおわれているが，これらのうらのいくつかは表 面から突き出しているものもあり, 污染の要因として危 険な状態にある.

\section{3 形 状}

特に定まった形状は示さず種々の形状の介在粒子が存 在しているが，全体として介在粒子は平面的であり，試 薬びんの厚さ方向に薄く存在している. 1 例安示すと Photo. 1 のと抢りである.

\section{4 組 成}

テフロン中に多数の介在粒子が存在することを述べた が，ここでは介在粒子の組成をレーザーマイクロプロー ブによって分析した.

介在粒子はいずれもテフロン中に埋まっているため直 接レーザーを当てることができないので，あらかじめ拡 大鏡下で介在粒子を中心に切断しテフロン中より露出さ

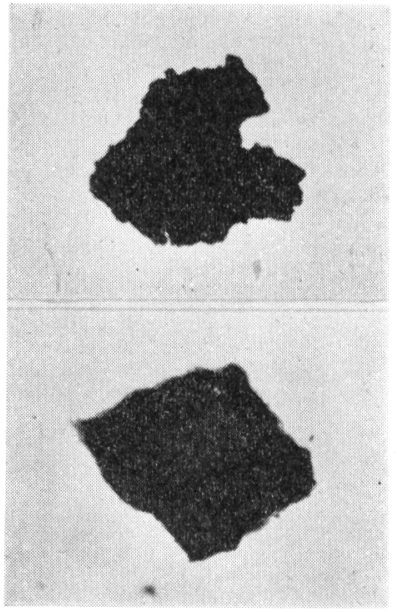

Photo. 1 Particle in Teflon $(\times 150)$

せた・この際介在粒子は容易に二分されたことから金属 そのままの幑粒子ではなく酸化物になっているようであ る.このことは別の測定の際，白金板上に介在粒子を 含むテフロンをとり加熱してテフロンを飛散させたとき に, 白金板上に残った介在粒子の形状, 大きさが最初に 認められたものより微細化してしまったことからも推察 された.

テフロン製試薬びん（容量 $200 \mathrm{ml}$ ) より，大きさ， 形状，色の異なる介在粒子 30 個を選び上記の方法で介 在粒子を露出させたのち、レーザーマイクロプローブに より分析した結果を Table III に示した.

Table III に見られるように, 介在粒子の主成分注鉄 およびその合金，チタン，アルミニウム，カルシウムで ある. カルシウム进除く他の成分製造装置からの污染 と考觉るのが妥当であり, カルシウムについては離型郕 に使われているのではなからうか，検出された元素がい ずれも広く一般に存在していることは容器としての使用 に際し注意しなければならない点である。

\section{5 鉄の含有量}

介在粒子に含まれる成分を代表して鉄の定量莸試及 た・試料を白金ボート上にとり，窒素ふえい気下 $500^{\circ} \mathrm{C}$ で大部分のテフロンを揮散させたのち，空気中で然焼 灰化し残さを白金ボートごとビーカーに入れ硝酸と硫酸 を用いて残さを分解した・白金ボートを取り除いて硫酸 白煙を発生さ也ほとえど乾固するまで濃縮したのち, ローフェナントロリン吸光光度法によって定量した. 結果 它Table IV に示した.

3.1 でも述ベたが, 試薬びえ中には, ペレットに比べ 
Table III Qualitative analysis of particles in Teflon by the laser microprobe

\begin{tabular}{|c|c|c|c|c|c|c|c|c|c|}
\hline Particle & $\mathrm{Al}$ & $\mathrm{Ca}$ & $\mathrm{Cr}$ & $\mathrm{Cu}$ & $\mathrm{Fe}$ & $\mathrm{Mg}$ & $\mathrm{Ni}$ & $\mathrm{Si}$ & $\mathrm{Ti}$ \\
\hline 1 & $\operatorname{tr}$ & H & - & $\operatorname{tr}$ & - & \# & - & + & + \\
\hline 2 & $\operatorname{tr}$ & m & - & $\operatorname{tr}$ & + & \# & + & + & 曲 \\
\hline 3 & - & + & - & - & - & + & - & $\mathrm{tr}$ & - \\
\hline 4 & - & + & - & $\operatorname{tr}$ & $\operatorname{tr}$ & $H$ & - & $\mathrm{tr}$ & - \\
\hline 5 & - & $H$ & - & $\mathrm{tr}$ & m & $H$ & - & + & - \\
\hline 6 & $\operatorname{tr}$ & \# & - & + & 冊t & $H$ & $\operatorname{tr}$ & + & H \\
\hline 7 & $\operatorname{tr}$ & + & - & - & - & $\operatorname{tr}$ & - & - & - \\
\hline 8 & H & 曲 & - & $\operatorname{tr}$ & 冊 & 冊 & - & 曲 & HII \\
\hline 9 & - & $H$ & - & - & $H$ & \# & - & $\mathrm{tr}$ & - \\
\hline 10 & - & m & - & $\operatorname{tr}$ & + & H & $\operatorname{tr}$ & + & - \\
\hline 11 & + & 册 & - & + & 世 & + & - & $H$ & $\mathrm{tr}$ \\
\hline 12 & $\operatorname{tr}$ & H & \#\# & + & H & + & H & $H$ & H \\
\hline 13 & - & $H$ & - & + & $\operatorname{tr}$ & + & + & $\operatorname{tr}$ & - \\
\hline 14 & $H$ & \# & - & + & $H$ & + & - & + & - \\
\hline 15 & - & W & - & $\operatorname{tr}$ & + & $H$ & - & $H$ & - \\
\hline 16 & 册 & 册 & m & $\operatorname{tr}$ & 冊 & H & $\operatorname{tr}$ & 冊 & 冊t \\
\hline 17 & 冊 & ·册t & $H$ & $\operatorname{tr}$ & 曲 & 曲 & - & 册t & HI \\
\hline 18 & + & 曲 & - & $\operatorname{tr}$ & + & H & - & + & $H$ \\
\hline 19 & - & + & - & + & $\operatorname{tr}$ & + & - & + & - \\
\hline 20 & - & 世 & - & $\operatorname{tr}$ & $\operatorname{tr}$ & H & - & + & H \\
\hline 21 & + & $H$ & 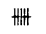 & \# & 册 & + & \#\# & $H$ & - \\
\hline 22 & - & H & - & - & + & $H$ & - & $\mathrm{tr}$ & - \\
\hline 23 & - & H & - & $\operatorname{tr}$ & + & + & - & + & - \\
\hline 24 & - & + & - & - & $H$ & + & - & + & - \\
\hline 25 & - & $H$ & - & $\operatorname{tr}$ & + & H & - & + & - \\
\hline 26 & - & + & - & - & $\operatorname{tr}$ & + & - & + & - \\
\hline 27 & - & + & - & - & $\operatorname{tr}$ & + & - & + & - \\
\hline 28 & - & + & - & - & $\operatorname{tr}$ & $\operatorname{tr}$ & - & + & - \\
\hline 29 & + & 册 & - & - & 冊 & 冊 & $\operatorname{tr}$ & \# & - \\
\hline 30 & - & H & 册 & H & 曲 & + & 册t & + & - \\
\hline
\end{tabular}

Table IV Contents of iron in Teflon

\begin{tabular}{cccc}
\hline & $\begin{array}{c}\text { Sample taken } \\
(\mathrm{g})\end{array}$ & $\begin{array}{c}\text { Iron found } \\
(\boldsymbol{\mu} \mathrm{S})\end{array}$ & $\begin{array}{c}\text { Iron } \\
(\mathrm{ppm})\end{array}$ \\
\hline Bottle (A Co.) & 5.75 & 103 & 18 \\
Pellet (A Co.) & 5.25 & $<2.5$ & $<0.5$ \\
" (C Co.) & 5.64 & 7.5 & 1.3 \\
\hline
\end{tabular}

て多量の鉄が検出された. Table IV の結果では，テフ ロン試薬びん中に $18 \mathrm{ppm}$ の鉄が検出されたが，テフロ ンとポリエチレンでは比重に差（テフロンはポリエチレ ンの約 2.4 倍）があるので, 容積あたりでポリエチレン （通常鉄 $0.5 \mathrm{ppm}$ 以下）と比較して約 100 倍の鉄が含 まれていることになる.

\section{交献}

1) D. E. Robertson : Anal. Chem., 40, 1067 (1968).

2) E. G. Kuehner, D. H. Freeman (M. Zief, Ed.): "Purification of Inorganic and Organic Materials", p. 297 (1969), (Marcel Dekker, Inc., New York).

$$
\text { is }
$$

Inorganic particles in plastic containers. Toshiaki Kuroha (The Central Research Laboratory, The Furukawa Electric Co., Ltd., Shinagawa-ku, Tokyo)

In the case of research of ultrapure materials, manufacturing, analysis and containers are most important. It is impossible to produce pure materials without any one of these items. Polyethylene has been widely used for containers of ultrapure materials on a commercial basis. However, it is not so stable with strong acids. Teflon is the best one of many plastics protected from reagent as strong acids or alkalies and also against temperature. It is natural that Teflon, having these good properties, is considered to be good containers. However, the particles in Teflon being contained as metalic and oxide compounds of inorganic materials become a problem. Therefore, this investigation was carried out to confirm numbers, size, distribution and constituents of particles in plastics, especially in Teflon, with microscope and laser micro probe.

Particles in the Teflon bottles were from less than several microns to about 200 microns and many were less than 50 microns in diameter. Over about 5 microns particles which were detected with microscope were found in bottles about four or five times more than in pellets. Quantity of particles in plastics were $7 \sim 20 \times 10^{3} / \mathrm{cm}^{3}$ in Teflon, $9 \times 10^{2} / \mathrm{cm}^{3}$ in polyethylene and $7 \times 10^{2} / \mathrm{cm}^{3}$ in polypropylene bottles. As a result of this fact, it is known that the contamination was occurred remarkably during the process of molding from pellets to bottles. All particles distributed throughout and embdded in the Teflon bottles, in some cases the covering layer was very thin and the particles produced a rough inner surface in the bottles, and their state contaminates easily the storage materials. Particles in the Teflon bottles were analyzed and found that iron, titanium, magnesium, calcium and silicon as the major constituents, and nickel, chromium, copper and manganese as the minor constituents using the laser micro probe. Their colors were black, dark brown, white and others. The contents of iron, one of the typical element contained in the particles, were determined by 1-10 phenanthroline method and were $18 \mathrm{ppm}$ in Teflon bottle and $<0.5 \mathrm{ppm}$ in original Teflon pellet.

(Received Oct. 22, 1971) 